\title{
Terra Szék. Terra Sulza. K pôvodu názvu obce Hozelec a močaristého územia medzi Gánovcami a Hôrkou na Spiši
}

\author{
Venujem pamiatke znamenitého českého jazykovedca \\ profesora Vladimíra Šmilauera (1895-1983)
}

ABSTRAKT: Autor príspevku na základe výskumu archívnych prameňov určil pôvod a význam niektorých prírodných a sídliskových názvov, ktoré sa v minulosti vyskytovali v priestore močaristých území na Spiši. V multietnickom prostredí regiónu sa močaristé plochy zaznamenávali slovenskými výrazmi slatina/luh, madarským pojmom szék či nemeckými slovami Sulza/Sulz. Uvedené pojmy sa v stredoveku stali základom pomenovania viacerých vodných tokov, území i sídiel na Spiši.

SŁowa KLuczowe: Slovensko, Spiš, Hozelec, močaristé územia, historická jazykoveda, historická geografia, stredovek.

Ked'v roku 1932 analyzoval legendárny český jazykovedec profesor Vladimír Šmilauer listinu Bela IV. z roku 1248, ktorou panovník vyjadril súhlas s predajom akejsi zeme ležiacej na území Gulz (terram in Gulz sitam) Pirinovi ${ }^{1}$, nazval pojem Gulz záhadným² ${ }^{2}$ Na spomínanej zemi sa vyvinuli Primovce (dnes čast' Hôrky)³. V roku 2005 sa autor tohto príspevku pokúsil vysvetlit predmetný pojem ako

1 Codex diplomaticus et epistolaris Slovaciae (dalej: CDSl), 2, (ed.): R. Marsina, Bratislava 1987, s. 202, nr. 289.

2 V. Šmilauer, Osídlení a národnosti Spiše. In: Bratislava, IX, 1935, s. 162.

$3 \mathrm{CDSl}, 2$, s. 202, nr. 289. Porovnaj s interpretáciou J. Endrődi, Od prvej písomnej zmienky do roku 1526. In: B. Malovcová a kol.: Hôrka. Minulost' a súčasnost' kopijníckych obcí. Hôrka 2014, s. 57-59. 
územie kyslých prameňov, resp. od pojmu kysel ${ }^{4}$. V roku 2019 počas výskumu archívnych prameňov sa podarilo zistit, že Hozelec sa v roku 1295 zaznamenal pojmom Sulza a v zozname spišských farností, ktorý bol vyhotovený pravdepodobne v poslednej tretine 16 . storočia ${ }^{5}, \mathrm{v}$ podobe Sulta ${ }^{6}$. Klúčová je v tomto smere listina z roku 1295, potvrdená v roku 1306 a prepísaná v roku 1330. Spišská kapitula 5 V 1330 prepísala na prosbu Gerarda a jeho synov z Chan listinu spišského opáta Jána a konventu Panny Márie na Spiši z roku 1306, ktorou menovaný opát potvrdil svoju vlastnú listinu z roku 1295 vo veci majetkovej časti comesa Menharda de Pulza a jeho synov7. Magda Feňarová prepísala sídlo Menharda v podobe de Pulza a spolu so sídlom Chan ich neidentifikovala ${ }^{8}$. Na základe štúdia originálu ${ }^{9}$ sme dospeli k záveru, že lokalitu, z ktorej pochádzal Menhard, treba čítat ako de Sulza. Vo vydaniach týchto prameňov v Madarsku bol pojem Sulza z listiny z roku 1306 síce správne prepísaný, ale nie identifikovaný1 ${ }^{10}$. O určenie názvov Chan a Sulza sa pokúsili autori, ktorí spracovali listinu z roku 1330. Pojem Sulza spojili podmienečne (s otáznikom) so spišskou obcou Zalužany ${ }^{11}$. Lokalitu Chan spojili s Nemešanmi ${ }^{12}$. Identifikácie oboch spomínaných lokalít nie sú správne. V skutočnosti sa názov sídla Sulza týkal Hozelca a Chan Gánoviec. V listine z roku 1317, ktorá sa týkala predaja istej zeme pri Filiciach (dnes čast' Gánoviec) a Stojanoch (zaniknutá stredoveká osada na území Popradu), vystupujú ako svedkovia synovia nebohého Menharda z Hozelca (Helbrandus et Menardus filii quondam Menhardi de Scek) ${ }^{13}$. Synovia Gerardus-a - Conczmannus

4 M. Števík, Z dejín osídlenia a verejnej správy stredovekého Spiša. Stará Lubovňa 2005, s. 49.

5 Prameň bude spracovaný v samostatnej štúdii, vrátane jeho datovania.

Lyceálna knižnica Kežmarok, Matricula Molleriana, č. 77, fol. 257 (dalej: Matricula).

M. Feňarová, Spišské prepošstvo. Stredoveké listiny 1248-1526. Bratislava 1964, s. 29, č. 47. V. Sedlák (ed.): Regesta diplomatica nec non epistolaria Slovaciae 1. Bratislava 1980, nr. 444, s. 205 (dalej: RDSl). Autor regestára lokalitu de Sulza neurčil. Pozri RDSl 1, s. 639.

M. Feňarová, c. d., index.

9 Magyar Országos Levéltár Budapest, (dalej: MOL) Dl 264160.

${ }^{10}$ G. Kristó (ed.): Anjou-kori oklevéltár. Documenta res Hungaricas tempore regum Andegavensium illustrantia II (1306-1310). Budapest 1992, s. 52, č. 105, 588.

${ }_{11}$ T. Almási, T. Köfalvi (eds.): Anjou-kori oklevéltár. Documenta res Hungaricas tempore regum Andegavensium illustrantia XIV (1330). Budapest 2004, s. 332, nr. 579, s. 479.

12 T. Almási, T. Köfalvi (eds.): Anjou-kori oklevéltár. Documenta res Hungaricas tempore regum Andegavensium illustrantia XIV (1330). Budapest 2004, s. 394, 456.

${ }^{13}$ MOL DF 262673; V. Sedlák (ed.): Regesta diplomatica nec non epistolaria Slovaciae 2. Bratislava 1987, s. 129, nr. 261; Preklad listiny publikoval J. Endrődi: Gánovce a Filice v stredoveku. In: B. Malovcová a kol.: Gánovce. Filice. Gánovce 2017, s. 82-83; M. Števík, Stredoveké dejiny Hozelca (13. storočie-1526). In: M. Hudák, M. Števík (zost.): Hozelec. Hozelec 2018, s. 80. 
a Gothsalcus zasa vystupujú v dokumente z roku 1320, ktorý sa týkal istého zálohu v Hozelci (Scek Mediocri) ${ }^{14}$. Z uvedeného je zrejmé, že Gerardus a jeho synovia Gochalkus a Kunchmannus z Chan, spomínaní v listine z roku 1330', pochádzali z Gánoviec a Menhard de Sulza z Hozelca. Dokument, obsahujúci vzácne údaje z rokov 1295, 1306 a $1330^{16} \mathrm{k}$ dejinám Hozelca i Gánoviec nebol dosial, ani pri tvorbe monografii ${ }^{17}$, využitý, pričom významným spôsobom obohacuje poznanie najstarších dejín týchto sídiel. Uvedené zistenia výrazne rozšírili interpretačné možnosti pôvodu názvu nielen obce Hozelec. Na tomto mieste je potrebné poznamenat, že viaceré močaristé územia na Spiši v období stredoveku nadobudli madarské pomenovanie szék vo význame bažina, močaristé miesto. Správne na to upozornil v roku 1993 archeológ František Javorsky ${ }^{18}$. S uvedeným pojmom sa stretáme napríklad v roku 1298, ked panovník Ondrej III. podaroval Jánovi, synovi Mikuláša, zem in Zeek (zem v szék) ${ }^{19}$. Na tomto území sa vyvinuli Baldovce ${ }^{20}$, obec $s$ výskytom minerálnych vôd ležiaca západne od Spišského Podhradia. Ked' sa v roku 1314 táto zem, resp. dedina stala predmetom predaja, zaznamenaná bola pod mad’arským názvom terra Vyfoluzek v zmysle zem Nová dedina szék (močiar, bažina) ${ }^{21}$. Tu je potrebné poznamenat, že obec, ktorá sa

${ }_{14}$ RDSl 2, nr. 570, s. 262; M. Števík, c. d. (2018), s. 80.

15 T. Almási, Köfalvi T. (eds.): Anjou-kori oklevéltár. Documenta res Hungaricas tempore regum Andegavensium illustrantia XIV (1330). Budapest - Szeged 2004, s. 394, 456.

${ }_{16}$ MOL, Dl 264160.

17 J. Endrődi k dejinám Gánoviec uvádza najstaršie dokumenty z rokov 1317 a 1346 (J. Endrődi, c. d. (2017), s. 82-84). M. Števík k dejinám Hozelca uvádza najstaršie dokumenty z rokov 1280, 1320 a 1322 (M. Števík, c. d., (2018), s. 75-83).

${ }_{18}$ F. Javorský, Kronika písaná v zemi. In: F. Žifčák (ed.): Kronika mesta Spišské Podhradie slovom a obrazom. Doplnené druhé vydanie. Košice 2011, s. 11.

${ }^{19}$ G. Wenzel (ed.): Árpadkori új okmánytár, vol. 12. Budapest 1874, s. 622, nr. 495.

${ }^{20}$ M. Števík, c. d. (2005), s. 49.

${ }^{21}$ RDSl 1, nr. 1256, s. 532; nr. 1257, s. 533; V. Rábik, Spišský župan Bald(uin) (1290-1301) a spoločenské pomery na Spiši za vlády posledného Arpádovca. In: Studia aecheologica Slovaca mediaevaia, V, 2006, s. 37. Autor nesprávne uviedol, že Baldovce boli v roku 1522 spustnutým sídlom s názvom „predii Baldorf” (MOL, Dl 69 25). V skutočnosti sa záznam týkal Novej Lesnej. Ide o nepresný záznam pomenovania Waldorf (M. Števík, Pustnutie a zánik písomne doložených sídiel v stredoveku a začiatkom novoveku na hornom Spiši (povodie Popradu a Dunajca). In: M. Števík (ed.): Spiš v 12. a 13. storočí. Stará Lubovňa 2011, s. 125). Praedium Waldorf sa spomína spoločne so susednými obcami - Velkou Lomnicou a Huncovcami, čo jednoznačne dokladá jeho stotožnenie s Novou Lesnou. Baldovce existovali aj na začiatku 16. storočia. V obci Baldowecz boli v roku 1529 zdanené dve porty (M. Števík, Najstaršie zachované portálne súpisy Spiša z prvej tretiny 16. storočia. In: M. Števík (ed.): K dejinám Podolínca a novovekého Spiša. Stará L'ubovňa 2006, 130). 
vyvinula za spomínaným močaristým územím, dnešné Nemešany, sa pôvodne nazývala villa Salasan (1249) - Zalužany ${ }^{22}$, teda dedina za luhami ${ }^{23}$. Pojem luh má význam aj vlhký terén pri rieke, resp. vlhký les ${ }^{24}$, resp. luža ako kaluž, baži$n^{25}$. V roku 1358 sa potok pretekajúci obcou Hrišovce, ktorý sa v súčasnosti nazýva Slatvinka, uvádzal v podobe Zeekpatak ${ }^{26}$. Obec Slatvina sa názvom Zeek spomína v roku $1311^{27}$, v roku 1598 ako Slatwyna ${ }^{28}$. Súvislost' medzi madarským pojmom szék a slovenským výrazom slatvina nie je na tomto mieste uvádzaná náhodne. Pojem slatina charakterizuje „močaristú plochu“. Vychádza z praslovanského výrazu solt-ina ako odvodenina praslovanského výrazu soltb, ktorý je odvodzovaný od praslovanského pojmu solb. V ruskom dialekte sa pojmom solot pomenúva močiar. Starosloviensky pojem pre slanú, močaristú pôdu znie Slatina ${ }^{29}$. Rovnako pomenovania vodných tokov, ktoré pretekajú močaristým územím s výskytom minerálnych prameňov medzi Hôrkou a Gánovcami či v okolí Baldoviec charakterizujú vlastnosti týchto vôd v zmysle štava (z praslovanského výrazu sbčava), voda s kyslou chutou ${ }^{30}$. Dnešný Klčovský potok, tečúci cez Baldovce je v roku 1249 doložený pojmom Cheunuk ${ }^{31}$ a v roku $1322 \mathrm{v}$ podobe Scheunik ${ }^{32}$. Pasienok pri Baldovciach sa v roku 1339 spomína pod názvom Chew$n i k^{33}$. Potok pretekajúci južne od Hozelca i Hôrky, dnes nazývaný Gánovský, sa v roku 1256 zaznamenal v podobe Seunek ${ }^{34}$.

Vrátme sa k okoliu Primoviec (dnes na území Hôrky), ktoré sa mali v roku 1248 vyvinút na zemi Gulz. Ked’ v roku 1349 vyhotovil testament farár Kostola sv. Ladislava v Spišskom Štvrtku Volmar, obyvatelov Kostola sv. Ondreja (dnes

${ }^{22}$ CDSl 2, s. 229, nr. 329; M. Števík, Stredoveká zaniknutá osada na Spiši (Zalužany)? In: M. Števík (ed.): K dejinám Podolínca a novovekého Spiša. Stará Lubovňa 2006, s. 107.

${ }^{23}$ B. Polla, Stredoveká zaniknutá osada na Spiši (Zalužany). Bratislava 1962, s. 152.

${ }^{24}$ L. Králik, c. d., s. 335.

25 V. Šmilauer, c. d. (1932), s. 470.

${ }^{26}$ I. Nagy (ed.): Codex diplomaticus patrius, VII. Budapest 1880, s. 452; M. Števík, c. d. (2005), s. 50.

27 J. Bárdossy (ed.): Supplementum analectorum terrae Scepusiensis. Leutschoviae 1802, s. 142.

${ }^{28}$ MOL, Conscriptiones portarum, E 158, fol. 274.

${ }^{29}$ L. Králik, Stručný etymologický slovník slovenčiny. Bratislava 2016, s. 537. Obdobná argumentácia V. Šmilauer, Vodopis starého Slovenska. Praha 1932, s. 469.

${ }^{30}$ L. Králik, c. d., s. 592-593.

${ }^{31} \mathrm{CDSl} 2$, s. 230, nr. 329.

32 M. Feňarová, c. d., nr. 35.

${ }^{33}$ M. Feňarová, c. d., nr. 59.

${ }^{34} \mathrm{CDSl} 2$, s. 362, nr. 522. 
na území obce Hôrka) označil ako populi de Sulta ${ }^{35} / G u l t a^{36}$ apud Sanctum Andream. Konkrétne mal dokument na mysli akiste vtedajších obyvatelov sídiel v okolí Kostola sv. Ondreja (Sv. Ondrej, Kišovce, Hôrka, Komárovce, Primovce a Miklušovce). Oblast’ medzi Gánovcami a Hôrkou (medzi ktorými leží aj Hozelec) je známa akumuláciou minerálnych vôd ${ }^{37}$. Ked’ sa v roku 1270 v susedstve Primoviec spomínala dedina Komárovce, ležala na území nazvanom szék (Comarfolua in Seek) ${ }^{38}$. V roku 1256 podaroval Belo IV. Filovi, Filovmu synovi, zem troch jutár in Sceek ${ }^{39}$. Na tomto území vznikli Filice (dnes súčast’ Gánoviec).

Obec Hozelec sa po roku 1280 vyvinula na zemi, majetku, nazývanom possessio Seek ${ }^{40}$. V predmetnom dokumente, ohraničení tohto majetku sa pojem szék použil jednak na pomenovanie majetku (Possessio Seek), zeme (terra Zek), ako aj vody vyvierajúcej z travertínovej kopy (aqua Zek) ${ }^{41}$. Prvá písomná zmienka o Hozelci sa zachovala z roku 1294 v podobe Zeyk ${ }^{42}$, druhá z roku 1295 v podobe Sulza ${ }^{43}$. Počas stredoveku sa obec pomenúvala výrazmi: Mediocris Scek $(1322)^{44}$, Felzeck $(1366)^{45}$, Hozulcz $(1429)^{46}$, Hozelcz $(1506)^{47}$, Hosulzt $(1520)^{48}$. V posled-

${ }^{35}$ MOL, DL 1029. Porovnaj J. Endrődi, c. d., s. 236-237. Ján Endrődi formu zápisu Sulta neuvádza.

${ }^{36}$ MOL, DF 272916. Porovnaj J. Endrődi, c. d., s. 236-237.

37 S. Hanigovská, L. Pixová, K. Verčimáková, Uhličité minerálne vody Východného Slovenska a možnosti ich využitia. In: Acta Montanistica Slovaca, roč. 13, 2008, č. 2, s. 262.

${ }^{38}$ MOL, Dl 26733; J. Endrődi, c. d., s. 71.

${ }^{39}$ CDSl 2, s. 362, nr. 522.

${ }^{40}$ MOL, DL 70452; M. Števík, Stredoveké dejiny Hozelca. In: M. Hudák, M. Števík (zost.): Hozelec. Hozelec 2018, s. 75.

${ }^{41}$ M. Števík, c. d. (2018), s. 76.

42 J. Vencko, Dejiny štiavnického opátstva na Spiši. Ružomberok 1927, s. 319. Za prvú písomnú zmienku o Hozelci určil rok 1294 autor tohto príspevku.

${ }^{43}$ MOL, Dl 264160. Za druhú písomnú zmienku o Hozelci určil rok 1295 autor tohto príspevku.

${ }^{44}$ V. Sedlák (ed.): RDSI 2, nr. 802.

${ }^{45}$ G. Fejér (ed.): Codex diplomaticus Hungariae ecclesiasticus ac civilis. Tom IX, vol. 3. Budae 1834, s. 630 .

${ }^{46}$ MOL, Dl 75022; B. Iványi, A márkusfalvi Máriássy család levéltára 1243-1803. I. In: Különlenyomat a Közlemények Szepes vármegye multjából. Lőcse 1917, s. 128; M. Števík, c.d. (2018), s. 89.

${ }^{47}$ MOL, Dl 22562.

${ }^{48}$ Matricula, č. 77, fol. 5-8; M. Števík, K dejinám stredovekých farností na Spiši. In: $Z$ minulosti Spiša, XXIV, 2016, s. 25. 
nej tretine 16. storočia, ako už bolo uvedené, je zaznamenaná v podobe Sulta ${ }^{49}$. $\mathrm{Z}$ uvedeného vyplýva, že močaristé územia na Spiši sa pomenúvali madarským výrazom $s z e ́ k^{50}$. Madarský pojem szék, resp. szík vo význame bažina spomína už Vaclav Šmilauer v roku 193251. Ján Endrődi uvádza záznam z roku 1316, v ktorom sa zaznamenávajú palludes, que vulgariter sech vocatur - močiare, bariny, ktoré sú ludovo zvané $\operatorname{sech}^{52}$. Ako v týchto súvislostiach interpretovat záznamy vztahujúce sa na Hozelec či okolie Hôrky - Gulz (1248), Sulza (1295), Sulta, Gulta (1349), (Ho)zulcz (1429), (Ho)zelcz (1506), (Ho)sulzt (1520), Sulta (posledná tretina 16. storočia)? Zdá sa, že odpoved treba hladat’ v nemeckom výraze Sülze, resp. Sulz, ktorý má pôvod v starej hornonemčine v podobe sulza vo význame slaná voda $\left(\right.$ Salzwasser) ${ }^{53}$, resp. v pojme strednej hornonemčiny v podobe sul$z e$ vo význame solanka (Salzlache), bahno, močiar (Schlamm) ${ }^{54}$. Pojem die Sül$z e$ sa $\mathrm{v}$ súčasnej nemčine používa aj $\mathrm{v}$ zmysle solanka, resp. slaná minerálna voda. Argumentáciu ohladom výrazu sulza podporuje okrem iného existencia rovnomenných sídiel v Nemecku (Sulza, Bad Sulza) ${ }^{55}$. V mestečku (Bad) Sulza sa vyskytujú horúce pramene, resp. slané kúpele ${ }^{56}$.

Z uvedeného vyplýva, že pojmy szék - slatina - sulza/sulze - luh/luža - štiavnik sa v minulosti nevyskytovali na močaristých územiach s minerálnymi prameňmi náhodne. $V$ multietnickom prostredí Spiša nebolo nič nezvyčajné, že sa významovo súvisiace pojmy zaznamenávali v latinských dokumentoch $\mathrm{v}$ slovenskom, madarskom či nemeckom jazyku. Základ pomenovania Hozelca či okolia Hôrky (sulza/sulze) je rovnaký, ako tomu bolo v prípade pomenovania obce Slatvina. Teda tieto výrazy pomenúvali močaristé, bahnité plochy s výskytom minerálnych vôd. V prípade Hozelca a okolia Hôrky sa použil nemecký výraz sulza, v prípade Slatviny slovenský výraz slat(v)ina. Popri nemeckom a sloven-

${ }^{49}$ Matricula, č. 77, fol. 257.

${ }^{50}$ F. Javorský, c. d., s. 11.

${ }^{51}$ V. Šmilauer, c. d., s. 470.

${ }^{52}$ MOL, Dl 68778; J. Endrődi, c. d. (2017), s. 79.

53 T. Starck, J. C. Wells, Althhochdeutsches Glossenwörterbuch (einschließlich des von Taylor Starck begonnenen Glossenindexes). Heidelberg (1972 -) 1990, s. 606; Wolf-Armin Frhr. v. Reitzenstein: Lexikon Schwäbischer Ortsnamen. Herkunft und Bedeutung. München 2013, s. 368 .

54 Wörterbuch der mittelhochdeutschen Urkundesprache, s. 1689; Wolf-Armin Frhr. v. Reitzenstein: c. d., 368 .

$55<$ https://www.de.wikipedia.org/wiki/Sulza; https://pl.wikipedia.org/wiki/Bad_Sulza>

$56<$ https://www.pl.wikipedia.org/wiki/Bad_Sulza> 
skom pojme sa alternatívne uvádzalo na pomenovanie spomínaných území slovo madarského pôvodu v podobe szék.

Pokial ide o prvú čast' názvu Hozelca $(H o)$, je vel’mi pravdepodobné, že má rovnaký či obdobný význam, aký sa používal pri pomenovaní obce v mad’arskom (fel) či latinskom jazyku (mediocris) - polovičný, stredný, prostredný. Uvedené pomenovanie by malo z pohladu polohy Hozelca (medzi Gánovcami a Hôrkou), teda v strednej časti predmetného močaristého územia s výskytom minerálnych prameňov, svoje opodstatnenie.

Záverom možno zhrnút, že na pomenovanie močaristého územia s výskytom minerálnych vôd tiahnuceho sa od Filíc (Gánoviec) cez Hozelec až po Komárovce (Hôrku) sa v minulosti používal mad’arský výraz szék, ako aj nemecké slovo sulza rovnako, ako tomu bolo v prípade slovenského výrazu slatvina, ktoré sa zasa uplatnilo pri názve obce Slatvina. V prípade močiarov v okolí Baldoviec sa slovenský výraz luh/luža použil pri pomenovaní dediny Zalužany (dnešné Nemešany), ležiacej z pohladu Spišského Podhradia za luhami.

\section{Summary}

\section{Terra Szék. Terra Sulza. On the Origin of the Names of the Village of Hozelec and the Swamp between Gánovce and Hôrka in Spiš}

On the basis of the studied archival sources the author explains the origins and meaning of place names and names of settlements that appeared in the past in the wet and marshy areas of Spiš. In the multi-ethnic environment of the region these areas were named using the Slovak words slatinal luh, the Hungarian term szék or German words Sulza/Sulz. The foregoing terms provided grounds for the formation of names of many watercourses, territories and human settlements in Spiš.

KEYWORDS: Slovakia, Spiš, Hozelec, swamp areas, toponymy, historical geography, Middle Ages. 


\section{Bibliografia}

\section{Źródła drukowane}

Anjou-kori oklevéltár. Documenta res Hungaricas tempore regum Andegavensium illustrantia II (1306-1310), (ed.): Kristó G., Budapest 1992.

Anjou-kori oklevéltár. Documenta res Hungaricas tempore regum Andegavensium illustrantia XIV (1330), (ed.): Almási T., Köfalvi T., Budapest 2004. Árpadkori új okmánytár, (ed.:) Wenzel G., vol. 12. Budapest 1874.

Codex diplomaticus et epistolaris Slovaciae, 2, (ed.): R. Marsina, Bratislava 1987, s. 202 , nr 289.

Codex diplomaticus Hungariae ecclesiasticus ac civilis. Tom IX, vol. 3, (ed.): Fejér G., Budae 1834.

Codex diplomaticus patrius, VII, (ed.): Nagy I., Budapest 1880.

Regesta diplomatica nec non epistolaria Slovaciae 1, (ed.): Sedlák V., Bratislava 1980. Supplementum analectorum terrae Scepusiensis, (ed.): Bárdossy J., Leutschoviae 1802.

\section{Literatura}

Endrődi J., Od prvej písomnej zmienky do roku 1526. In: B. Malovcová a kol.: Hôrka. Minulost' a súčasnost' kopijníckych obcí. Hôrka 2014.

Endrődi J.: Gánovce a Filice v stredoveku. In: Malovcová B. a kol.: Gánovce. Filice. Gánovce 2017, s. 82-83.

Feňarová M., Spišské prepošstvo. Stredoveké listiny 1248-1526. Bratislava 1964.

Hanigovská S., Pixová L., Verčimáková K.atarína, Uhličité minerálne vody Východného Slovenska a možnosti ich využitia. In: Acta Montanistica Slova$c a$, roč. 13,2008 , č. 2.

Iványi B., A márkusfalvi Máriássy család levéltára 1243-1803. I. In: Különlenyomat a Közlemények Szepes vármegye multjából. Lőcse 1917.

Javorský F., Kronika písaná v zemi. In: Žif̌cák F., Kronika mesta Spišské Podhradie slovom a obrazom. Doplnené druhé vydanie. Košice 2011.

Králik L., Stručný etymologický slovník slovenčiny. Bratislava 2016.

Polla B., Stredoveká zaniknutá osada na Spiši (Zalužany). Bratislava 1962.

Rábik V., Spišský župan Bald(uin) (1290 - 1301) a spoločenské pomery na Spiši za vlády posledného Arpádovca. In: Studia aecheologica Slovaca mediaevaia, V, 2006.

Starck T., Wells John C., Althhochdeutsches Glossenwörterbuch (einschließlich des von Taylor Starck begonnenen Glossenindexes). Heidelberg 1990.

Šmilauer V.,Vodopis starého Slovenska. Praha 1932. 
Šmilauer V., Osídlení a národnosti Spiše. In: Bratislava, IX, 1935.

Števík M., Z dejín osídlenia a verejnej správy stredovekého Spiša. Stará Lubovňa 2005.

Števík M., Najstaršie zachované portálne súpisy Spiša z prvej tretiny 16. storočia. In: Števík M. (ed.): K dejinám Podolínca a novovekého Spiša. Stará L’ubovňa 2006.

Števík M., Stredoveká zaniknutá osada na Spiši (Zalužany)? In. Števík M. (ed.): K dejinám Podolínca a novovekého Spiša. Stará Lubovňa 2006.

Števík M., Pustnutie a zánik písomne doložených sídiel v stredoveku a začiatkom novoveku na hornom Spiši (povodie Popradu a Dunajca). In: Števík M. (ed.): Spiš v 12. a 13. storočí. Stará Lubovňa 2011.

Števík M., K dejinám stredovekých farností na Spiši. In: Z minulosti Spiša, XXIV, 2016.

Števík M.,Stredoveké dejiny Hozelca (13. storočie-1526). In: Hudák M., Števík M. (zost.): Hozelec. Hozelec 2018.

Vencko J., Dejiny štiavnického opátstva na Spiši. Ružomberok 1927.

Wolf-Armin Frhr. v. REITZENSTEIN: Lexikon Schwäbischer Ortsnamen. Herkunft und Bedeutung. München 2013.

$<$ https://www.de.wikipedia.org/wiki/Sulza; https://pl.wikipedia.org/wiki/Bad_Sulza> $<$ https://www.pl.wikipedia.org/wiki/Bad_Sulza> 